\title{
Case report: a diagnostically challenging conjunctival mass caused by the Epstein-Barr virus
}

\author{
Jordan V. Chervenkoff ${ }^{*}$, Saul N. Rajak ${ }^{1}$, Paul G. Brittain ${ }^{1}$, David A. Wright ${ }^{2}$ and Victoria J M Barrett ${ }^{1}$
}

\begin{abstract}
We present a paediatric case of infectious mononucleosis in a 13-year old, manifesting with follicular conjunctivitis and a conjunctival mass in one eye with no evidence of leucocytosis on the blood count. The diagnosis was confirmed following surgical excision and biopsy. The case represented a diagnostic challenge due to its atypism and given the steady increase in the prevalence of EBV-related ocular diseases in the last years, this report can serve as an example to prompt earlier serological tests to identify the aetiology in similar cases. This is important because EBV can be treated with acyclovir early in the active viral phase.
\end{abstract}

\section{Introduction}

The Epstein-Barr virus (EBV) is a double-stranded DNA human herpes virus type 4 (HHV-4) [1]. It is transmitted mainly through oral secretions and establishes latency by invading memory B-cells, resulting in a high prevalence throughout the world (about $90 \%$ of adults are lifelong carriers) [2, 3]. Primary EBV infection generally occurs asymptomatically in the early years of life but in adolescence its hallmark is infectious mononucleosis (IM) [4,5]. Viral proliferation induces both cellular and humoral immunologic responses and there is an increase in the overall number of mononuclear lymphoid cells. Thus, the condition usually presents with malaise, sweats, lymphadenopathy, fever and pharyngitis [6]. Blood results often demonstrate marked leucocytosis with a high differential lymphocyte cell count and atypical enlarged lymphoid cells.

In ophthalmology, EBV has been implicated as a causative agent in various ocular malignancies and infections which affect mostly the anterior segment (as a whole EBVrelated ocular diseases have been on the rise in the past decade) [7-9]. The virus has a preference for mucosaassociated lymphoid tissues (MALT), which are rich in B lymphocytes, such as the conjunctiva or the lacrimal glands [9-11].

* Correspondence: jordan.chervenkoff@gmail.com

'Sussex Eye Hospital, Eastern Road, Brighton BN2 5BE, UK

Full list of author information is available at the end of the article
In this article we present a case of an EBV-related follicular conjunctivitis with an unusual unilateral bulbar and subtarsal mass in a paediatric patient, which was diagnostically challenging due to the atypical blood picture.

\section{Case report}

A 13-year old boy presented to the accident and emergency with a large painless conjunctival mass under the right upper eyelid. It had been first noticed two weeks previously in the right supranasal quadrant and had gradually increased in size since then. No itching or excessive lacrimation were reported. The child had had a febrile illness and had been complaining of malaise, intermittent chills and sore-throat in the past 4 days. Otherwise, no significant past medical or ophthalmic history was reported and he was not on any medication. In addition, there were no known allergies.

On examination, there was no pain during extraocular movements (EOM), no proptosis or diplopia. Vision was normal (Snellen acuity of 6/9) in both eyes. The intraocular pressure (IOP) was $18 \mathrm{mmHg}$ bilaterally. Conjunctival follicles were present on the upper and lower eyelids in both eyes. The mass was obvious on lid retraction involving both the bulbar and subtarsal conjunctiva. It was salmon-pink, non-tender and spread across the entire conjunctiva superior to the limbus with no corneal involvement, as seen on Fig. 1a. It had well delineated borders. Pupils were equal and reactive to light. The anterior 


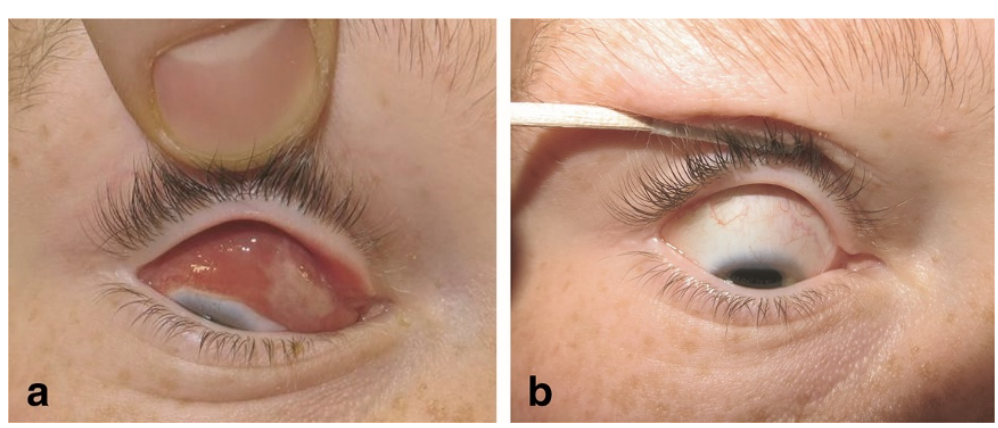

Fig. 1 Pre-operative extend of lesion (a) and post-operative outcomes (b)

chamber was deep and clear and no abnormalities were detected in the posterior segment.

The boy's temperature was $37.9{ }^{\circ} \mathrm{C}$. One lymph node was palpable on the left and two on the right-all in the upper cervical chain. They were mobile and non-tender. There was no organomegaly on palpation.

Blood tests indicated that serum alanine transaminase (ALT) was elevated at $60 \mathrm{IU} / \mathrm{L}$ (normal range: 0-41 IU/L) and haemoglobin was slightly low at $131 \mathrm{~g} / \mathrm{L}$ (normal range: $135-180 \mathrm{~g} / \mathrm{L}$ ). The overall and differential white blood cell counts (WBC) were normal, as illustrated on Table 1.

A successful excision was performed under general anaesthetic and the mass was sent for a biopsy. Postoperative results at 7 days were excellent (Fig. 1a and b). The general symptoms had subsided and the child had regained his normal function. There was a small residual lymph node palpable on the left in the upper cervical chain.

\section{Discussion}

Diagnosing the lesion was challenging and initially two types of malignancies were considered: rhabdomyosarcoma and lymphoma. Conjunctival MALT lymphoma is the commonest malignant orbital tumour and it is characteristically described as a "salmon-patch" on the conjunctiva often arising from the fornix [12]. However, it characteristically presents later in life than the age of the patient (median 65 years) [13]. On the other hand, rhabdomyosarcoma is a common primary orbital

Table 1 Total leucocyte and differential cell counts

WBC: $5.9 \times 10^{9} / \mathrm{L}$ (normal range: $4.0-11.0$ )

Differential:

Neutrophils $2.0 \times 10^{9} / \mathrm{L}$ (normal range: $2.0-7.5$ ) $34.1 \%$

Lymphocytes $3.2 \times 10^{9}$ (normal range: $1.3-3.5$ ) $54.5 \%$

Monocytes $0.6 \times 10^{9}$ (normal range: $\left.0.2-0.8\right) 9.9 \%$

Eosinophils $0.0 \times 10^{9}$ (normal range: $0.0-0.4$ ) $0.5 \%$

Basophils $0.1 \times 10^{9}$ (normal range: 0.0-0.1) $1 \%$ malignancy that can present with conjunctival swelling starting in the superonasal segment [14]. The majority of cases are observed in the first 10 years of life and progress rapidly giving rise to visual disturbances due to proptosis or limited EOM $[14,15]$. Other differentials to consider include malignant processes such as ocular infiltration secondary to multiple myeloma or infective causes such as nodular anterior scleritis, chlamydia, herpetic infection, papilloma, tuberculosis and migratory phlyctenulosis [16].

The histological report of the excised mass demonstrated a population of large atypical centroblastic CD20 positive cells. These large proliferating B cells are representative of EBV in the active latent stage [17]. A T-cell mediated response against the rapidly dividing $B$ cells usually occurs in non-immunocompromised individuals [18]. Hence, the conjunctival enlargement was the result of the accumulation of histiocytes, pleomorphic lymphoid and plasma cells. Additionally, thirty to forty percent of both $\mathrm{B}$ and $\mathrm{T}$ cell nuclei expressed Epstein-Barr encoded RNAs (EBERs). Multiple polyclonal cell populations were detected by polymerase chain reaction (PCR) looking for TCR or IGH gene rearrangements. This was in keeping with a reactive, rather than a neoplastic process [19].

Serology revealed the presence of Epstein-Barr nuclear antigen (EBNA) immunoglobulin G (IgG) and EBV capsid antigen immunoglobulin $M$ (IgM) antibodies. Viral EB DNA was detected at low levels at less than 1000 copies $/ \mathrm{ml}$. This serological profile was consistent with the histological findings of a recent acute immunoreactive process against EBV. Notably, the presence of EBNA IgG was indicative of the virus establishing latency following primary infection (the serological genome detection assay was performed 42 days after the initial presentation) [5].

The case we presented was challenging because lymphocytosis (a characteristic feature of IM) was not evident on the full blood count at initial presentation which was about two weeks after the onset of symptoms. Normally a relative or absolute increase in the number of 
lymphocytes (with a $15-25 \%$ increase in atypical cells) would be expected within the first 14 days [20]. Due to the cross-reactivity of some of the antibodies, the Monospot test can be used to confirm the diagnosis [20]. Its specificity is close to $100 \%$ (96-100 \%), however because about $10 \%$ of people do not produce heterophil antibodies it is less sensitive (70-92\%) [21]. A clinical picture highly suggestive of IM in addition to a positive Monospot test can be used to exclude other causes of infectious mononucleosis such as: cytomegalovirus (CMV), herpes symplex, Toxoplasma gondii and human immunodeficiency virus type I (HIV-1).

Retrospectively, the elevated ALT presented a clue due to the characteristic elevation of liver transaminases in IM [22]. As a difference, alkaline phosphatase and gammaglutamyl transpeptidase levels do not usually change in IM.

Young patients with suspicious lymphoid periocular lesions with a recent history of a febrile illness, malaise, lymphadenopathy, pharyngitis and other presenting features of IM should be offered a full blood count and serological studies to check for recent EBV infection or reactivation. If the aetiology is viral and depending on the extent of the mass, surgical management can be offered, as in our case. Otherwise, acyclovir can be used because the EB virus is susceptible to it in the active phase. Moreover, there have been reports where spontaneous regression of a smaller nodule of similar origin was observed, which demonstrated that conservative treatment may also be an option [23].

\section{Summary points}

We presented a case of an EBV-related conjunctival mass in a paediatric patient with a recent primary infection and symptoms of infectious mononucleosis. The blood picture was not fully characteristic and the instance emphasised the importance of recognising the early signs of IM and treating accordingly. Ultimately, surgical excision was performed and the child had a successful recovery shortly after.

\section{Consent}

Written informed consent was obtained from the patient's parents for publication of this Case report and any accompanying images. A copy of the written consent is available for review by the Editor of this journal.

\section{Competing interest}

The authors declare that they have no competing interests.

\section{Authors' contribution}

$J C$ drafted and submitted the manuscript. SR helped draft the manuscript, provided clinical details and macroscopic photographs of the lesion. PB critically reviewed the manuscript. DW critically reviewed the manuscript and provided histological analysis of the tissue. VB critically reviewed the manuscript. All authors read and approved the final manuscript.

\section{Author details}

'Sussex Eye Hospital, Eastern Road, Brighton BN2 5BE, UK. ${ }^{2}$ Royal Sussex County Hospital, Brighton BN2 5BE, UK.

Received: 23 February 2015 Accepted: 9 September 2015

Published online: 07 October 2015

\section{References}

1. Tao Q, Young LS, Woodman CB, Murray PG. Epstein-Barr virus (EBV) and its associated human cancers-genetics, epigenetics, pathobiology and novel therapeutics. Front Biosci. 2006;11:2672-713.

2. Eriko M, Masaaki A, Shigeru K, Nobuyuki K, Takeharu Y, Naoto H, et al. Spectrum of Epstein-Barr virus-related diseases: a pictorial review. Jpn 」 Radiol. 2009;27(1):4-19

3. Pereira MS, Blake JM, Macrae A. EB virus antibody at different ages. Br Med J. 1969;4(5682):526

4. Kutok JL, Wang F. Spectrum of Epstein-Barr virus-associated diseases. Annu Rev Pathol. 2006;1:375-404.

5. Niller $\mathrm{HH}$, Wolf $\mathrm{H}$, Minarovits J. Regulation and dysregulation of Epstein-Barr virus latency: implications for the development of autoimmune diseases. Autoimmunity. 2008:41(4):298-328.

6. Luzuriaga K, Sullivan JL. Infectious mononucleosis. N Engl J Med 2010;362(21):1993-2000.

7. Matoba AY. Ocular disease associated with Epstein-Barr virus infection. Surv Ophthalmol. 1990;35(2):145-50.

8. Ongkosuwito JV, Van der Lelij A, Bruinenberg M, Doorn MW-V, Feron EJC, Hoyng CB, et al. Increased presence of Epstein-Barr virus DNA in ocular fluid samples from HIV negative immunocompromised patients with uveitis. Br J Ophthalmol. 1998;82(3):245-51.

9. Faroog AV, Shah A, Shukla D. The role of herpesviruses in ocular infections. Virus Adaptation and Treatment. 2010;2:115-23.

10. Crouse C, Pflugfelder S, Cleary T, Demick S, Atherton S. Detection of Epstein-Barr virus genomes in normal human lacrimal glands. J Clin Microbiol. 1990;28(5):1026-32.

11. Jones DT, Monroy D, Ji Z, Atherton SS, Pflugfelder SC. Sjögren's syndrome: cytokine and Epstein-Barr viral gene expression within the conjunctival epithelium. Invest Ophthalmol Vis Sci. 1994;35(9):3493-504.

12. Valvassori GE, Sabnis SS, Mafee RF, Brown MS, Putterman A. Imaging of orbital lymphoproliferative disorders. Radiol Clin North Am. 1999;37(1):135-50

13. Cohen SM, Petryk M, Varma M, Kozuch PS, Ames ED, Grossbard ML. Non-Hodgkin's Lymphoma of Mucosa-Associated Lymphoid Tissue. Oncologist. 2006;11(10):1100-17.

14. Dagher R, Helman L. Rhabdomyosarcoma: an overview. Oncologist. 1999:4(1):34-44.

15. Shields JA, Shields CL. Rhabdomyosarcoma: Review for the Ophthalmologist**. Surv Ophthalmol. 2003;48(1):39-57.

16. Rospond-Kubiak I, Brazert A, Kociecki J, Breborowicz J. Poststreptococcal syndrome mimicking conjunctival lymphoma. BMC Infect Dis. 2013;13:149.

17. I wakiri $D$, Takada K. Role of EBERs in the pathogenesis of EBV infection. Adv Cancer Res. 2010;107:119-36.

18. Masucci MG, Gavioli R, de Campos-Lima PO, Zhang QJ, Trivedi P, Dolcetti R. Transformation-associated Epstein-Barr virus antigens as targets for immune attack. Ann N Y Acad Sci. 1993;690:86-100.

19. García MJ, Martínez-Delgado B, Granizo JJ, Benítez J, Rivas C. IgH, TCR-[gamma] and TCR-[beta] Gene Rearrangement in 80 B-and T-Cell Non-Hodgkin's Lymphomas: Study of the Association Between Proliferation and the So-called" Aberrant" Patterns. Diagn Mol Pathol. 2001;10(2):69-77.

20. Fleisher GR, Collins M, Fager S. Limitations of available tests for diagnosis of infectious mononucleosis. J Clin Microbiol. 1983;17(4):619-24.

21. Elgh F, Linderholm M. Evaluation of six commercially available kits using purified heterophile antigen for the rapid diagnosis of infectious mononucleosis compared with Epstein-Barr virus-specific serology. Clin Diagn Virol. 1996; $7(1): 17-21$.

22. Markin RS. Manifestations of Epstein-Barr virus-associated disorders in liver. Liver. 1994:14(1):1-13.

23. Gardner BP, Margolis TP, Mondino BJ. Conjunctival lymphocytic nodule associated with the Epstein-Barr virus. Am J Ophthalmol. 1991;112(5):567-71. 